\title{
PROGRAM PEMBERDAYAAN MASYARAKAT KOTA DENPASAR MELALUI KADER PAUD UNTUK MENINGKATKAN KETRAMPILAN PENGASUHAN BERDASAR PERKEMBANGAN PSIKOLOGIS ANAK
}

\author{
L.K.P.A. Susilawati ${ }^{1}$ dan N.M.A. Wilani ${ }^{2}$
}

\begin{abstract}
ABSTRAK
Pendidikan anak usia dini merupakan pondasi penting dalam pengembangan potensi anak secara menyeluruh sehingga peran kader PAUD dalam mendidik anak usia dini menjadi sumber daya yang penting. Untuk itu, pengembangan pemahaman dan ketrampilan kader PAUD dalam melakukan pendidikan anak usia dini perlu dibekali dengan pengetahuan dan pemahaman tentang tahapan perkembangan psikologis anak usia dini. Pemberdayaan masyarakat ini diharapkan mampu memberikan ketrampilan pengasuhan berdasar perkembangan psikologis anak. Kegiatan pemberdayaan masyarakat ini meliputi penyuluhan tentang tahapan perkembangan psikologis anak, diskusi kelompok menganalisa kasus permasalahan perkembangan anak usia dini, serta pelatihan menggunakan kalimat positif dalam berkomunikasi dengan anak usia dini. Hasil kegiatan adalah program pemberdayaan melalui metode penyuluhan, FGD (focus group discussion) kasus, dan pelatihan dapat menambah wawasan dan pemahaman kader PAUD tentang perkembangan psikologis anak, dalam melakukan identifikasi kondisi seputar perkembangan anak usia dini, serta dalam menggunakan kalimat positif secara tepat kepada anak didik maupun dalam melakukan sharing kepada orangtua anak di PAUD.
\end{abstract}

Kata Kunci : kader PAUD, keterampilan, potensi, perkembangan anak, pendidikan anak usia dini

\begin{abstract}
Early childhood education is an important foundation in the development of children's potential so that the role of early childhood cadres in educating young children is an important resource. To that end, the development of understanding and skills of early childhood cadres in early childhood education needs to be equipped with knowledge and understanding of early childhood psychological development stage. Community empowerment is expected to provide parenting skills based on the psychological development of children. Community empowerment activities include counseling about the phases of child psychological development, group discussions analyzing cases of early childhood development problems, as well as training using positive sentences in communicating with early childhood. The result of the activity is the empowerment program through the extension method, focus group discussion, and the training can increase the insight and understanding of PAUD cadres about the psychological development of the child, in identifying the conditions surrounding early childhood development, and in using positive sentences appropriately to the child educate and in sharing to parents of children in early childhood.
\end{abstract}

Keywords : early childhood cadres, skills, potential, child development, early childhood education

\footnotetext{
${ }^{1}$ Staf Pengajar Jurusan Psikologi Fakultas Kedokteran Universitas Udayana, pandeary@unud.ac.id

${ }^{2}$ Staf Pengajar Jurusan Psikologi Fakultas Kedokteran Universitas Udayana, ariwilani@unud.ac.id
} 


\section{PENDAhUluan}

Jumlah PAUD banjar mengalami peningkatan setiap tahunnya (www.kotadenpasar.go.id). Hal ini berarti meningkatnya kesadaran orang tua terhadap pendidikan anak sejak usia dini. Pendidikan anak usia dini adalah suatu upaya pembinaan yang ditujukan kepada anak sejak lahir sampai dengan usia 6 tahun yang dilakukan melalui pemberian rangsangan pendidikan untuk membantu pertumbuhan dan perkembangan jasmani dan rohani agar anak memiliki kesiapan dalam memasuki pendidikan lebih lanjut. PAUD banjar didirikan untuk membantu warga, terutama lebih meringankan dari segi biaya, lebih mempermudah secara jarak mengingat orang tua sibuk bekerja sehingga anak-anak bisa diantar oleh kakek atau neneknya. Berdasarkan survei pendahuluan, beberapa permasalahan dalam PAUD di banjar adalah:

a. Kualifikasi tingkat pendidikan dan latar belakang pendidikan para pendidik PAUD yang belum memenuhi persyaratan.

b. Kurang terpenuhinya persyaratan kualifikasi tingkat pendidikan dan latar belakang pendidikan para pendidik PAUD menyebabkan besarnya kebutuhan untuk mengetahui dan mengembangkan kurikulum.

Salah satu yang diupayakan adalah meningkatkan sumber daya pendidik dalam mendidik anak usia dini karena revolusi mental harus dimulai sejak usia dini. Karena pendidikan anak usia dini merupakan pondasi penting pendidikan sehingga pengembangan potensi anak secara menyeluruh menjadi penting dilakukan, terutama melalui pendidik PAUD. Pengetahuan dan pemahaman tentang tahapan perkembangan psikologis anak usia dini menjadi poin penting dalam program pemberdayaan masyarakat ini karena fakta di lapangan, pengetahuan dan pemahaman pendidik PAUD tentang anak usia dini dan perkembangannya masih terbatas sehingga berpengaruh terhadap cara yang dilakukan dalam proses layanan. Untuk itulah, program pemberdayaan masyarakat ini menyasar pada pendidik atau kader PAUD yang ada di banjar di wilayah Kota Denpasar untuk meningkatkan ketrampilan pada pendidik/kader PAUD tentang perkembangan psikologis anak.

\section{METODE PELAKSANAAN}

Alternatif pemecahan masalah yang dilakukan, yakni penyuluhan, FGD (focus group discussion), dan pelatihan. Metode kegiatan diawali dengan memberikan angket terbuka untuk menggali pengetahuan kader PAUD Kota Denpasar tentang perkembangan psikologis anak. Kegiatan dilanjutkan memberikan materi penyuluhan tentang perkembangan psikologis pada anak. Selanjutnya dilakukan diskusi berkelompok (focus group discussion) dengan kasus untuk mendapatkan pemahaman bersama sehingga terjadi perubahan pola berpikir tentang pengasuhan atau mendidik anak dengan berdasar perkembangan psikologis anak. Pada akhir kegiatan, dilakukan pelatihan menggunakan kalimat positif agar para kader PAUD memiliki ketrampilan komunikasi yang positif dalam menjalankan peran sebagai pendidik PAUD. Karena kalimat positif dapat mempengaruhi perkembangan psikologis anak, terutama di masa dini tumbuh kembang. Setiap sesi disediakan waktu tanya jawab untuk memberikan kesempatan kepada kader PAUD menyampaikan pertanyaan. Tahap akhir dilakukan evaluasi keberhasilan kegiatan. Pemilihan beberapa metode tersebut berdasarkan kebutuhan para kader PAUD terhadap wawasan dan ketrampilan tentang perkembangan psikologis anak dalam melakukan pendidikan di PAUD.

\section{HASIL DAN PEMBAHASAN}

Program pengabdian kepada masyarakat dilaksanakan pada hari Rabu, tanggal 5 Oktober 2016 selama satu hari penuh dengan mengambil lokasi di rumah Pintar milik Dinas Pendidikan Pemuda dan Olahraga Kota Denpasar. Para peserta dalam kegiatan pengabdian adalah para kader atau pendidik PAUD banjar di lingkup Kota Denpasar yang berasal dari empat kecamatan, yaitu 
kecamatan Denpasar Barat, kecamatan Denpasar Timur, kecamatan Denpasar Utara, dan kecamatan Denpasar Selatan.

Pada tahap awal kegiatan, peserta mengisi angket terbuka tentang tahap perkembangan anak usia 25 tahun Berdasarkan data 40 peserta pengabdian yang mengisi angket terbuka tentang tahap perkembangan anak usia 2-5 tahun, didapatkan hasil bahwa sebagian besar $(72,5 \%)$ kader / pendidik PAUD di Kota Denpasar belum memiliki pengetahuan yang luas tentang spesifik tahap perkembangan anak pada setiap usia di fase dini usia $2-5$ tahun (Diagram 3.1). Hanya sebagian kecil $(7,5 \%)$ peserta yang memiliki pengetahuan tentang tahap perkembangan usia 2-5 tahun.

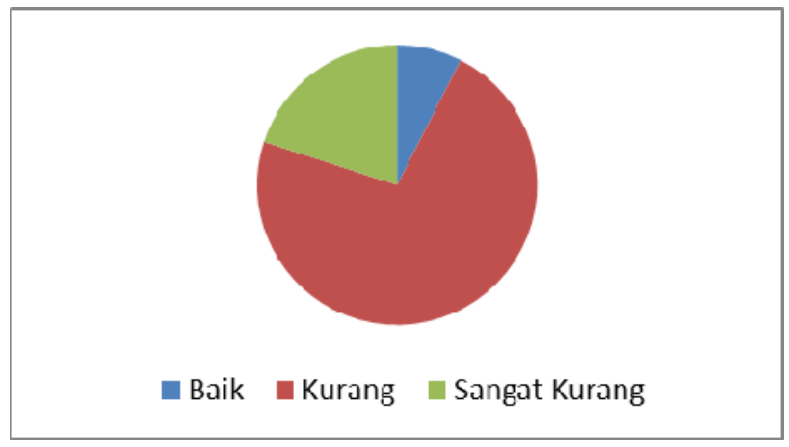

Gambar 3.1. Hasil Angket Terbuka

Tahap kedua adalah penyuluhan tentang "Mengenal Fase-Fase Perkembangan Anak Usia Dini Serta Menerapkan Pola Asuh Yang Efektif". Sesi tanya jawab berlangsung dalam tiga sesi dengan tiga orang penanya pada setiap sesi. Antusiasme peserta mulai terlihat karena narasumber banyak memberi contoh kasus perilaku bermasalah pada anak akibat penerapan pola asuh yang kurang tepat di usia dini yang direspon dengan pertanyaan seputar tips dalam pengasuhan dan peran dari tahap perkembangan dalam pengasuhan (Gambar 3.1). Penyuluhan dalam konteks pemberdayaan masyarakat memiliki arti mengembangkan daya yang sudah ada atau dimiliki di masyarakat menjadi lebih bermanfaat bagi masyarakat bersangkutan (Margono, 1978). Metode penyuluhan dianggap efektif dalam kegiatan ini karena dapat diterapkan oleh para kader PAUD dan dirasakan langsung oleh anak maupun orang tua.

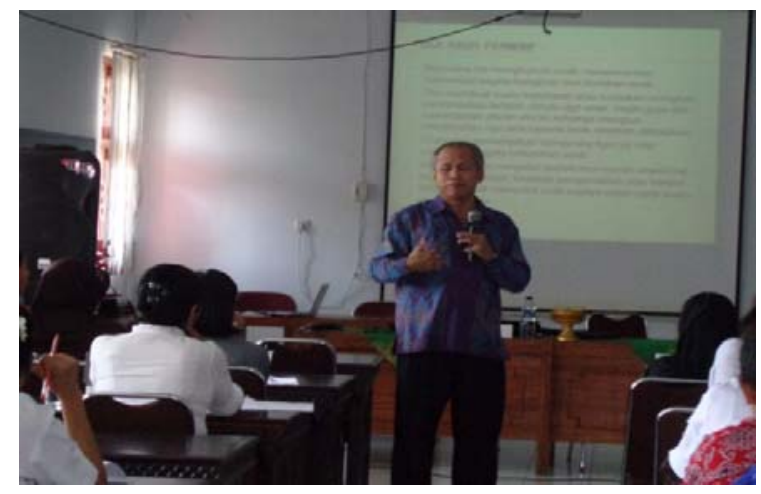

Gambar 3.2. Penyuluhan oleh Dr. I Made Rustika, M.Si, Psikolog

Tahap selanjutnya FGD (focus group discussion) dengan hasil sebagian besar peserta sudah mampu mengidentifikasi sumber permasalahan dan mampu menetapkan tindak lanjut dalam bentuk tahapan yang dilakukan untuk mengatasi permasalahan. Beberapa peserta juga mengajukan 
pertanyaan di luar kasus namun masih seputar masalah perkembangan psikologis anak dan dibahas bersama dengan peserta lain. Review kasus dipandu oleh ketua pelaksana pengabdian yang merangkap sebagai fasilitator (Gambar 3.3).

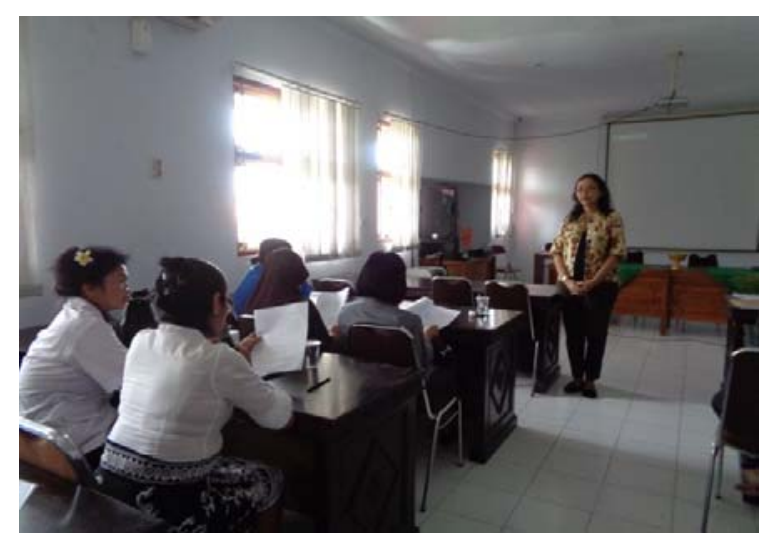

Gambar 3.3. FGD (focus group discussion) oleh Luh Kadek Pande Ary Susilawati, M.Psi.,Psikolog)

Tahap akhir kegiatan adalah pelatihan menggunakan kalimat positif dimana peserta diajak berlatih melalui contoh lima kalimat negatif dalam relasi orangtua dan anak usia dini. Lalu peserta diminta untuk menuliskan kalimat positif yang lebih tepat. Pada sesi tanya jawab secara interaktif, peserta nampak antusias mengajukan pertanyaan seputar penggunaan kalimat positif. Sebagian besar peserta mengakui kesulitan dan tidak mudah untuk mampu berpikir dengan cepat untuk menampilkan kalimat positif pada situasi yang dihadapi dengan anak (Gambar 3.3). Pelatihan merupakan kegiatan yang disengaja untuk memecahkan masalah sumber daya manusia dan atau masalah yang dihadapi oleh lembaga dalam upaya peningkatan produktivitas (Jhonson, dalam Craig 1976). Penggunaan kalimat positif menjadi sumber pemecahan masalah dalam bentuk komunikasi dari orang dewasa kepada anak-anak yang cenderung negatif.

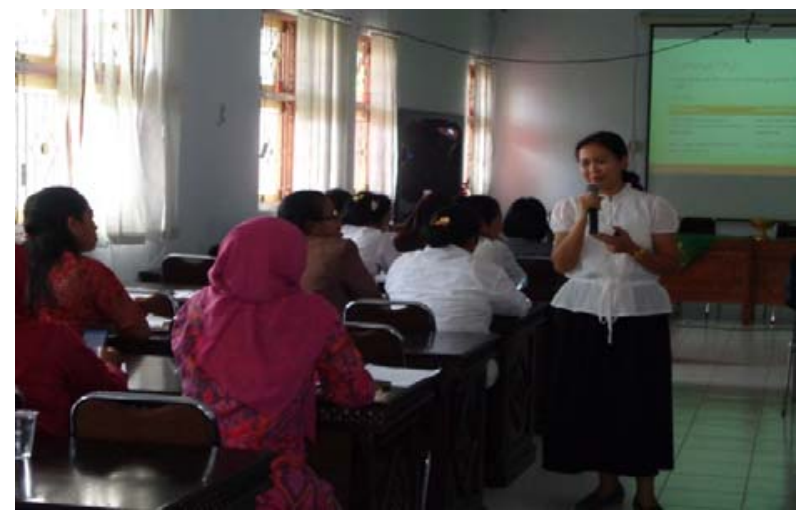

Gambar 3.4. Pelatihan oleh Ni Made Ari Wilani, M.Psi, Psikolog

Kegiatan ditutup dengan kesan dan pesan oleh peserta terhadap kegiatan ditunjukkan pada diagram dibawah (diagram 3.2). Kesan sebagian besar peserta tentang kegiatan pengabdian adalah bertambahnya wawasan dan pemahaman $(47,62 \%)$ dan dapat digunakan sebagai pedoman dalam mengajar anak di sekolah maupun di rumah $(33,33 \%)$. 

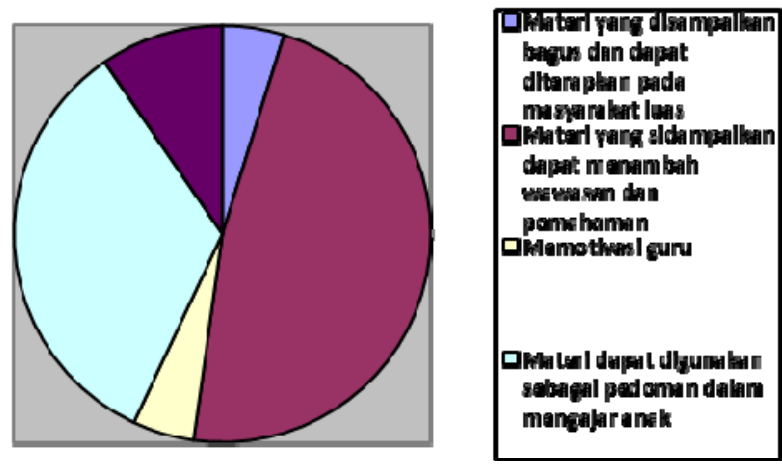

Gambar 3.5. Kesan Peserta Terhadap Kegiatan Pengabdian

Berdasarkan proses selama kegiatan pengabdian, peserta telah mengetahui dan mampu memahami, serta memiliki ketrampilan melalui latihan dalam melakukan pengasuhan kepada anak usia dini. Kegiatan pengabdian masyarakat melalui peningkatan ketrampilan pengasuhan berdasar perkembangan psikologis anak kepada kader/pendidik PAUD Kota Denpasar diharapkan mampu benar-benar meningkatkan mutu pendidikan kepada anak usia dini, baik dari segi metode pengajaran, inovasi materi, dan kreativitas dalam mendidik anak usia dini di PAUD.

\section{KESIMPULAN DAN SARAN}

Kegiatan pengabdian kepada masyarakat untuk meningkatkan ketrampilan pengasuhan berdasar perkembangan psikologis anak kepada kader PAUD di kota Denpasar yang dilaksanakan dengan metode penyuluhan, FGD (focus group discussion) kasus, dan pelatihan dapat menambah wawasan dan pemahaman tentang perkembangan psikologis anak, melakukan identifikasi kondisi seputar perkembangan anak usia dini, serta menggunakan kalimat positif secara tepat kepada anak didik maupun dalam melakukan sharing kepada orangtua anak di PAUD.

Berdasarkan peran kader PAUD dalam pendidikan anak usia dini, maka penting bagi kader PAUD untuk memiliki pengetahuan dan ketrampilan tentang tahapan perkembangan psikologis anak, bagaimana penggunaan kalimat yang positif dalam relasi dengan anak usia dini yang sedang mengalami masa perkembangan dan stimulasi, serta pemahaman terhadap kondisi anak di usia dini. Kegiatan pengabdian ini diharapkan mampu memberikan wawasan dan ketrampilan sehingga dapat diterapkan sehari-hari dalam peran sebagai kader PAUD.

\section{UCAPAN TERIMAKASIH}

Penulis mengucapkan terima kasih kepada LPPM Universitas Udayana yang telah memberikan dukungan dana sehingga pelaksanaan kegiatan ini dapat berjalan sesuai rencana. Ucapan terima kasih pula kepada para kader Paud perwakilan PAUD di Kota Denpasar yang telah berpartisipasi dalam kegiatan ini, serta kepada semua pihak yang telah mendukung kegiatan ini. 


\section{DAFTAR PUSTAKA}

Craig, R.L. (1976). Training and Development Handbook ; A Guide to Human Resource Development, New York : McGraw Hill Book Company.

Hurlock, E. (2004). Psikologi Perkembangan. Jakarta: PT Gramedia Pustaka.

Margono, S. (1978). Kumpulan Bacaan Penyuluhan Pertanian. IPB. Bogor.

PAUD Kota Denpasar. http://www.kotadenpasar.go.id. Diakses pada tanggal 13 Maret 2016.Nama Penulis (tahun). 